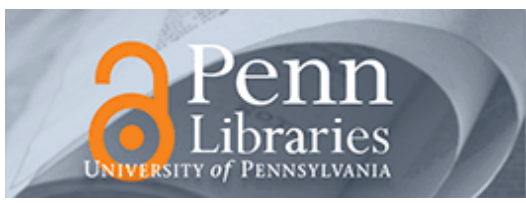

University of Pennsylvania ScholarlyCommons

Wharton Pension Research Council Working

Papers

Wharton Pension Research Council

9-1-2013

\title{
Actuarial Perspectives on Defined Benefit Pension Risk - Modeling Emerging Issues
}

Christopher M. Bone

Edth Limited LLC

Follow this and additional works at: https://repository.upenn.edu/prc_papers

Part of the Economics Commons

Bone, Christopher M., "Actuarial Perspectives on Defined Benefit Pension Risk - Modeling Emerging Issues" (2013). Wharton Pension Research Council Working Papers. 118.

https://repository.upenn.edu/prc_papers/118

This paper is posted at ScholarlyCommons. https://repository.upenn.edu/prc_papers/118

For more information, please contact repository@pobox.upenn.edu. 


\title{
Actuarial Perspectives on Defined Benefit Pension Risk - Modeling Emerging Issues
}

\begin{abstract}
This paper reviews documentation provided on the Pension Benefit Guaranty Corporation's (PBGC's) Pension Insurance Modeling System (PIMS). It also discusses priorities for future development of the system, based on emerging issues in pension plan design and environment, and it suggests particular emphasis be placed on improvements in refining the modeling of the multiemployer program.
\end{abstract}

\section{Disciplines}

Economics 


\title{
Actuarial Perspectives on Defined Benefit Pension Risk - Modeling Emerging Issues
}

\author{
Christopher M. Bone \\ September 2013
PRC WP2013-12
Pension Research Council Working Paper
Pension Research Council
The Wharton School, University of Pennsylvania
3620 Locust Walk, 3000 SH-DH
Philadelphia, PA 19104-6302 \\ Tel.: 215.898.7620 Fax: 215.573.3418 \\ Email: prc@wharton.upenn.edu \\ http://www.pensionresearchcouncil.org
}

The research reported herein was pursuant to a grant from the U.S. Social Security Administration (SSA) funded as part of the Retirement Research Consortium (RRC); the author also acknowledges support from The Pension Research Council at The Wharton School. All findings and conclusions expressed are solely those of the author and do not represent the views of the SSA or any agency of the federal government, the MRRC, the PRC, or The Wharton School at the University of Pennsylvania. All findings, interpretations, and conclusions of this paper represent the views of the authors and not those of the Wharton School or the Pension Research Council. (C2013 Pension Research Council of the Wharton School of the University of Pennsylvania. All rights reserved. 
Actuarial Perspectives on Defined Benefit Pension Risk - Modeling Emerging Issues

\begin{abstract}
$\underline{\text { Abstract }}$
This paper reviews documentation provided on the Pension Benefit Guaranty Corporation's (PBGC's) Pension Insurance Modeling System (PIMS). It also discusses priorities for future development of the system, based on emerging issues in pension plan design and environment, and it suggests particular emphasis be placed on improvements in refining the modeling of the multiemployer program.
\end{abstract}

\title{
Christopher M. Bone
}

Edth Limited LLC

130 Thatcher's Hill Road

Flemington, NJ 08822 


\section{Actuarial Perspectives on Defined Benefit Pension Risk - Modeling Emerging Issues}

Christopher M. Bone

The Pension Benefit Guaranty Corporation (PBGC) Pension Insurance Modeling System (PIMS) is a stochastic model used by PBGC to evaluate the risks to its single employer and multiemployer programs, and to evaluate the range of potential financial statuses of the programs in the near future. Secondary uses of the program include legislative analyses of pension funding requirements and of program guarantees. The system has also been made available to outside users with an interest in modeling the overall U.S. pension system (PBGC 2012b). PIMS was initially implemented for the single employer program (SE-PIMS). More recently, a separate version of PIMS has been developed, using and significantly revising the core PIMS functionality to examine financing of PBGC’s multiemployer program (ME-PIMS).

This paper is based on a review of documentation provided by PBGC regarding both SEPIMS and ME-PIMS, and various reports generated using the PIMS model; our review also suggests areas of further development and how they might be prioritized. Our view recognizes that development priorities are generally formulated within an environment of constrained resources and competing advice. Accordingly, we suggest prioritizing model development based on a quantified estimate of the impact of the changes on model results.

\section{The Status of the Multiemployer Program}

The development and deployment of the ME-PIMS program in 2009 was an important enhancement of PBGC's ability to model its potential risks. The effort was validated by the recent and unprecedented emergence in 2010 through 2012 of deficits reaching over \$1 billion in 
the Multiemployer Program (PBGC 2013b: Table M-1). These deficits are large not only in dollar terms, but also as a percentage of the resources of PBGC's Multiemployer program. Reported liabilities were almost four times the reported assets in 2012, and the 2012 deficit exceeded 50 times premium revenues (PBGC 2012a). Although premium amounts are scheduled to increase by $33 \%$ for 2013 , this is not nearly sufficient to repair the deficits facing the program (see Figure 1).

Figure 1 here

While one would not characterize the single-employer program as being in good health, its recent financial position shows a relatively more stable set of financial ratios than does the multiemployer program (see Figure 2).

Figure 2 here

The PBGC has used ME-PIMS to quantify the risk of insolvency in the program in recent reports (PBGC 2013a). These reports indicate a high likelihood of continued deterioration of program financial results and a significant probability that the program will run out of money if current law is continued. In fact, current law is not scheduled to be continued; current law funding rules are scheduled to expire at the end of the current Congressional session (i.e., after 2014). Expiration without further legislative action would result in the prior funding rules going back into effect, requiring even less funding of multiemployer plans and further increasing PBGC’s risk of insolvency and participant risks of benefit losses.

These issues combine to suggest that legislative activity and analysis needs will be important in the near future, and that continued improvement in the capabilities of ME-PIMS should remain a high priority for PBGC staff. After considering the relative stability of the SE- 
PIMS system, maintenance and improvement of ME-PIMS should arguably be the highest priority for PBGC staff overseeing PIMS.

Quality assurance. PBGC has commissioned a peer review of ME-PIMS (Buck Consultants 2012) as well as listings of known issues compiled by its software vendor (Lynchval Systems 2012). PBGC summarized the major issues in a disclaimer to its recent report to Congress as four potential changes to assumptions in the model and two other changes to ME-PIMS algorithms (PBGC 2013a). PBGC explicitly stated that the agency could not predict with confidence how these changes would alter model results. Not addressed in the disclaimer were the comments in the peer review report regarding: (a) system documentation; (b) ability to make programming changes; (c) system structure/organization; and (d) output. These comments in the peer review report generally amplify comments provided by the software vendor. It is important not to lose sight of these additional comments.

When an actuarial model is being developed to include new capabilities and new users, it is always a struggle to allocate resources to document quality assurance processes and to ease the testing and tabulation of results. But it is important that PBGC document the steps it takes to assure the quality of data inputs, verify the correctness of individual runs to test different policies, and ensure that the analyses are correct and complete. Written documentation that specifies the processes used to ensure accurate modeling allows management to better control the quality of the modeling process, particularly when modeling needs are urgent. While detailed documentation was not provided for review, agency comments indicate that PBGC has drafted a quality assurance procedures manual. The author encourages PBGC staff to periodically review these procedures and follow through on the recommendations in the peer review report (Buck Consultants 2012) regarding process and documentation and those in the system software vendor 
report (Lynchval Systems 2012) regarding replicability of results under different system configurations.

In establishing and revising quality assurance processes, PBGC may wish to informally confer with chief actuaries in other agencies that sponsor complex models, and also to reach out to professional actuarial organizations for assistance in assembling groups willing to share information on their processes. Given the rapidity of computational system changes, informal benchmarking may be more effective in designing or redesigning quality assurance policies that work within PBGC’s constraints than more formal survey processes.

Modeling cutbacks in participant benefits. The primary use of ME-PIMS is to look at risk from the perspective of PBGC's balance sheet. A secondary use of the model is to evaluate legislative proposals for changes to the rules that affect multiemployer program guarantees, premium levels, withdrawal liability rules, and funding requirements.

A useful addition to the model would be the ability to quantify reductions in participants’ accrued benefit rights. After decades where federal pension law was increasingly protective of accrued benefit rights, the Pension Protection Act (PPA) reversed course and allowed for certain cutbacks in accrued benefits (including reductions in early retirement subsidies) in the context of multiemployer plans deemed Critical and forced to adopt a rehabilitation plan. ME-PIMS models these types of behavior changes by plan sponsors. PBGC also applies cutbacks to guaranteed benefit levels when plans enter various stages in preparation for, or actual receipt of, financial assistance from PBGC. ME-PIMS also models these cutbacks (PBGC 2009).

Given the financial prospects for PBGC's current multiemployer program, legislative proposals are emerging (Defrehn and Shapiro 2013) that may provide additional methods of partially cutting back benefits for participants in severely underfunded plans as a preferable 
alternative to ultimate reliance on an, even smaller, level of PBGC guaranteed benefits. It could be helpful to policy-makers if PBGC could capture and report on the amount of benefit reduction generated in ME-PIMS at different stages, both in terms of the percentage reduction in benefits for participants in any year and the present value of such benefit reductions. This information would allow more informed comparison of the risks to participants from different legislative proposals (in addition to analyzing the risks to PBGC and the amount of increases in funding requirements).

SE-PIMS modeling of future benefit accruals. The past decades have seen many changes in the design of single employer pension plans, most of which have tended to lower the rate of future benefit accruals. Also many employers have adopted new forms of pension plans designed to more directly link benefits to the lump sum value of the compensation represented by the pension plan. Such plan designs, commonly referred to as cash balance and pension equity plans, are not currently modeled in PIMS, although there are plans to begin modeling cash balance plans (PBGC 2010: Section 1.2). Further, as rates of inflation have slowed and defined contribution (DC) account balances matured, many sponsors have changed the mix of retirement programs they provide to employees, cutting back or sometimes eliminating future accruals when updating pension plan designs. While it was once common for sponsors to amend career average pay plans to keep benefits up to date with salary changes and to provide ad hoc inflation adjustments to retirees, these activities have slowed dramatically of late. Further, more than a 
third of private DB pensions have in some way frozen benefit accruals (PBGC 2013b: Tables S36, S-37). ${ }^{1}$

PBGC's documentation acknowledges many of these changes are not reflected in its current model. For instance, PBGC does not model career average plans directly, but instead models a final average pay plan that provides equivalent current benefits. (PBGC 2010: Section 1.2) This has the effect of presuming future benefit changes in the career average pay plan which appear increasingly unlikely. (PBGC has plans to review this item.) Similarly, PBGC cannot model complicated plan benefit formulae, and it is not able to model many forms of intermediate plan freezes such as "soft" freezes or reductions in the rate of future benefit accruals.

PIMS documentation indicates that when the system is "trued-up” to match the liabilities reported on the Form 5500 and its schedules, the resulting normal cost has been overstated by about $30 \%^{2}$ (PBGC 2010: Section 1.2). Normal cost is a broad measure of the cost of benefits being earned. For this reason, overstatements in the normal cost may be indicative of a general overstatement in future liabilities. PBGC agency comments indicate that they have implemented changes to the system to separately true-up normal cost. Yet, this will not necessarily fix the problem of potentially overstating future benefit accruals, to the extent that PIMS ages the

${ }^{1}$ As of 2011, 36.1\% of Single-Employer Plans were partially or fully frozen and another 5.1\% of plans were closed to new entrants. These plans covered $27.6 \%$ and $12.8 \%$, respectively, of participants in active plans.

2 “An empirical test of the Schedule B/SB current liability normal cost amounts versus PIMS calculated results for 2007 shows an aggregate overstatement of the PIMS starting normal cost of 30\%.” 
population and continues to apply the unadjusted plan terms. In fact, it has the potential to further exacerbate the problem. ${ }^{3}$

How material these changes in plan design would be is unclear. Recent changes in pension law may better tie the funding of new accruals to the periods when they are earned. Many have speculated that the majority of the PBGC's exposures are "baked in" to the existing system. For this reason, it would be helpful for the PBGC to first use the PIMS model to quantify the relative contribution of future benefit accruals to its risk profile. It could do so by running PIMS with an assumption that all plans freeze and entirely cease future benefit accruals. To the extent that this test quantifiably demonstrates that PBGC's risk profile is primarily derived from existing benefit accruals, improvements to the model to refine the modeling of future benefit accruals may take on a low priority. But to the extent PBGC saw significant portions of its future risk arise from new benefit accruals, further research could help identify the source of that risk

${ }^{3}$ PIMS documentation is unclear on the specific coding used in the module that revalues the plan liabilities in future years. Portions of the documentation describe the plan population being aged and then valued directly under the terms of the plan (e.g. projected to each age of potential decrement with a benefit based on service to that point). Under this approach, end-stage adjustments to the normal cost will not reduce the rate of future accruals under the plan but will instead lead to the generation of liability losses, continuing to present a plan with larger liabilities due to future benefit accruals than are appropriate. Furthermore, by treating the phantom accruals as liability losses rather than as normal costs, the accruals would be amortized over time, making the plan appear to be worse funded than before the programming change to separately true-up normal cost. Thus careful testing is required to ensure that end-stage adjustments to the normal cost improve the model accuracy. 
by industry and plan type. Then higher priority would be needed to better reflect recent trends in plan design.

\section{Treatment of Contributions in SE-PIMS}

The reports generated using SE-PIMS make inconsistent assumptions regarding the employer contribution behaviors. For purposes of modeling the future funded status of plans, PIMS assumes that plan sponsors will make the minimum contribution possible to the plan, including using up any prepayment credits (“credit balances”) established due to sponsors contributing more than required in the past. Simultaneously, for purposes of modeling premium revenues, PBGC assumes that certain companies will improve the funded status of their pension plans, thereby reducing the amounts of variable rate premium collected (PBGC 2010: Section 3.4.7). Both assumptions cannot be simultaneously appropriate when modeling the path followed by an individual plan in a specific projection path. The resulting projections will only be reasonable if the resulting inconsistent assumptions do not materially affect results.

The use of the assumption that sponsors contribute at the minimum level is also quite inconsistent with experience since the new single-employer pension provisions went into effect. Furthermore, by embedding an assumption of minimum contributions, a progressive bias is introduced into the universe of pension plans' funded status. This bias grows with each projection year, such that the universe of plan funded status converges to a universe that has contributed at the current law minimum basis. Since PBGC's bankruptcy model assigns a higher likelihood of bankruptcy to sponsors of less well funded plans (PBGC 2010: Section 6.4), this serves to increase the relative probability that plan sponsors will be modeled as going bankrupt. By assuming that no sponsors pre-pay their pension contributions during good times, it also 
marginally increases the net pension contributions due in subsequent modeled downturns, leading to additional cash flow pressures and further increasing the risk of bankruptcy (see Figure 3).

Figure 3 here

Finally, the PIMS bankruptcy model assigns an $80 \%$ threshold value on funded status, assuming that if the sponsor's pension plans are, in aggregate, funded at more than $80 \%$, the plan sponsor will be able to marshal adequate resources in bankruptcy to avoid the picking up of the plan liabilities by PBGC (PBGC 2010: Section 4.2.6). PBGC presents this $80 \%$ threshold as a single number, but over time it moves from an assumption that the plan is $80 \%$ funded today, to an assumption that the plan will be $80 \%$ funded if the sponsor contributes only the minimum in the future.

Thus, the assumption that plan sponsors will fund at the minimum level increases both the projection of the number of sponsors that will go into bankruptcy in each future year and the likelihood that the bankruptcy will generate a claim. Finally, it assumes that the universe from which claims are drawn will be progressively less well funded than the case would be if current sponsor behavior were to be modeled.

The documentation provided by PBGC justifies this assumption without quantification, stating: "Plan sponsors often contribute more than the minimum required by law, and they create credit balances. However, firms in bankruptcy seldom have positive credit balances. Thus, estimates of expected loss based on the assumption that firms pay merely the minimum contribution, is a reasonable assumption of behavior” (PBGC 2010: Section 2.3.5). But this argument appears to fail due to circularity in subsequent modeled years. Furthermore, the argument assumes that the only path to a zero credit balance at bankruptcy is generated by 
contributing at the minimum contribution level, ignoring changes under PPA that will have the effect of forcing many sponsors to forego the future use of prepayment credits ("burn credit balances”) when plans fall below a certain funded status. This second path would also lead to bankrupt sponsors having a zero credit balance, but at higher asset levels than would obtain had the sponsor followed a minimum funding path.

Finally, the treatment of contributions above the minimum level is inconsistent with the treatment of contributions below the minimum level. PBGC's documentation notes that minimum contributions are often not made in the year a sponsor declares bankruptcy. It adjusts for this by backing the final contribution out of the assets (PBGC 2010: Section 4.2.8). PBGC does not assume that every sponsor fails to make minimum contributions just because sponsors in bankruptcy fail to do so. It would appear that PBGC could take a similar approach to credit balances at plan termination (subtracting them from the assets), rather than assuming that no plan sponsors made contributions in excess of the minimum contribution amount as this is clearly contrary to observed experience.

Based on the documentation, it should be possible to quantify the effect of using consistent contribution amounts within SE-PIMS by applying various assumptions to contribution behavior. There are two tests of interest. First is the comparison of results across projections with different contribution behavior assumptions. Second is the relative risk of bankruptcy shown in the $10^{\text {th }}$ year to that in the first year, as well as the relative funded status of plans hitting the $80 \%$ threshold, within projections based on a particular assumption. Both of these tests should be applied to determine whether this inconsistent assumption materially affects results. 
Integration with risk management operations and information. PBGC maintains a department focused on risk mitigation and management. Through a combination of programs (e.g., the “early warning program”, or the “4062 program”), PBGC monitors corporate events affecting the sponsors of many of the largest underfunded plans it insures (PBGC 2000). PBGC's 2012 report cited the agency's success in averting the termination of the American Airlines plans, keeping \$12 billion off PBGC’s books (PBGC 2012a). PBGC has recently announced changes to the 4062 program to focus it primarily on large employers assumed to present a risk to the agency (PBGC 2012c).

PBGC’s early warning and 4062 programs have resulted in negotiated agreements with the sponsors of many plans. Typically these agreements provide for additional protections to PBGC by providing for: (1) additional cash contributions to a pension plan; (2) letters of credit to secure promises to make future pension contributions or to backstop underfunded pension plan liabilities; (3) security interests in certain company assets; and (4) guarantees by exiting (better financed) members of a controlled group (PBGC 2000). These guarantees directly affect some of the most risky plans that SE-PIMS models. Additional cash contributions, negotiated by PBGC's risk management program, will be reflected in subsequent years as credit balances, but typically PBGC negotiates an agreement with the sponsor that does not allow the plan sponsor to use those credit balances. That is, typical provisions require the preservation of the credit balance when measured on an annual basis, but allow temporary access during a plan year. Letters of credit, security interests, and guarantees all affect the amount of assets available to PBGC as recovery, if an underfunded plan terminates. Yet information on these agreements does not appear to be coded in SE-PIMS, even though the model makes assumptions about the amount available as 
recovery and assumes (contrary to agreements negotiated with PBGC) that credit balances are spent in future projection years.

Failure to reflect the terms of PBGC's risk mitigation programs in its risk modeling software would appear to have two undesirable results. First, modeled outcomes may overstate PBGC's actual risk. Given the concentration of risk in PBGC's single employer program, this may be a significant item. Second, failure to reflect the results of the risk mitigation strategy in the risk modeling program deprives agency management of a tool to evaluate the advantages of policy changes to risk management programs, such as those recently announced for the 4062 program.

Finally, attention to the risk mitigation strategy and its results in SE-PIMS leads to the recognition that opportunities for risk mitigation are very different in the multiemployer program and raises the issue of whether risk mitigation tools and strategies should be made available to PBGC for that program through legislative or regulatory innovation. The ability to model any such proposals and their effect on plan, PBGC, and participant finances would better inform any such proposals.

Of course, incorporating new data into PIMS is an extensive process that would require additional resources that might better be dedicated to more significant development opportunities. For this reason, we suggest that PBGC begin by assigning quantified upper and lower range bounds on the SE-PIMS model results which would flow from the incorporation of data from the early warning, 4062, and other risk mitigation programs such as were used in the American Airlines case.

Mortality assumptions. PIMS was initially designed on the analogy of modeling the occurrence of net claims under a casualty insurance program that insures against rare events. But once a 
claim has been accepted, PBGC functions much as a life insurer / annuity provider, whose risks are based largely on investment returns and mortality. PIMS models different investment return environments, but it does not assign any additional risk for the chance that mortality rates will differ from an assumed base rate.

This likely is influenced by PBGC’s highly unusual approach to setting mortality and interest rates used to value liabilities. At PBGC's inception, PBGC had no mortality experience with which to determine pricing, so instead set up the agency set up a process to survey annuity insurer pricing. PBGC then took a standard industry mortality table and solved for the interest rates needed to closely replicate average prices from the annuity survey. In recent years, PBGC has had sufficient data to study mortality among a large fraction of the single employer plans it has trusteed and has reflected those mortality rates to a limited extent. But the agency continues to use the same approach to setting the combination of interest rates and revised mortality, to match the average settlement prices derived from its annuity survey. This has led to situations where PBGC has determined that it needed to strengthen its mortality assumption (i.e. assuming longer lives) being tied to a weakening of the interest rate assumptions, so that the resulting maturity values continue to match the survey. ${ }^{4}$

A problem with this approach is that it implicitly assumes that the price for settlement annuities in the insurer survey represents the price it would cost to cover a program with PBGC's

${ }^{4}$ SE-PIMS documentation indicates that a similar approach is taken to determine the mortality table used in SE-PIMS, but in this case mortality rates are adjusted so as to approximate settlement rates when interest rates are based on Treasury rates, rather than PBGC's valuation rates (PBGC 2010: Section 4.2.1). Comments by Agency indicate that this is an error in the documentation which will be corrected. 
mortality. In other words, it assumes that the insurers are pricing a longevity risk that is identical or very similar to PBGC's. Furthermore, it assumes that mortality rates will be the same for PBGC's single employer program and multiemployer program, despite differences in longevity rates demonstrated in the literature based on factors including geography, union membership, lifetime income, and educational attainment. These factors could easily generate significant differences in mortality rates between those underlying PBGC's annuity survey and the rates experienced by the populations for whom it will provide benefits.

In the U.K., there is widespread interest and a robust annuity market, which in conjunction with increases in life expectancy, has led to increased interest in models for projecting increases in life expectancy. This has also prompted new ways to manage the risk of changes in assumed mortality risks by insurers in both the U.K. and U.S. In the U.S., plan sponsors are also beginning to recognize and value the effects of assuming excess longevity risk, and to incorporate the issue qualitatively in discussions about pension derisking (Banham 2013). PIMS does not currently model this aspect of risk.

Moreover, there are reasons to question whether the current process of setting rates to match an insurer survey is likely to become increasingly divergent from PBGC's own experience. This is due to the issue of selection as reflected in insurer prices due to participants being offered lump sums.

Insurer group annuity pricing has historically been thought to reflect some adverse selection due to the common practice of allowing participants the option of a lump sum at plan termination, instead of receiving an annuity from the insurer (this is particularly common during times when interest rates are high; Society of Actuaries Group Annuity Experience Committee 1996). Recent plan “derisking” options at certain large employers have also featured the option 
of a lump sum vs. annuitization (Banham 2013). In addition, newer plan designs have tended to include the option of taking a lump sum at termination or retirement. Indeed this is more or less a standard feature of cash balance and pension equity plans now, and it is also common in other plans. But, PPA restricts the ability of participants to utilize this option in poorly funded plans which are, of course, those more likely to land at PBGC in the future. Hence PBGC's experience of adverse selection is likely to increasingly diverge from that experienced by insurers in its annuity survey.

The issue of how PBGC should adjust its valuation practices to reflect changes in longevity and the annuity market goes beyond PIMS. But it is notable that PIMS has no provision to model the risk of mortality rates differing from the assumed base case, nor for the rate of improvement in mortality to differ from that assumed. This is likely to be a more important consideration for ME-PIMS, where cash flow testing of projected dates of insolvency is much in demand. The ability of ME-PIMS to directly model cash flows, as opposed to the use of maturity values in SE-PIMS (PBGC 2009), may make it both important and easier to address this issue first within the ME-PIMS system. But, because the duration of the standard ME-PIMS runs typically extend out only one or two decades, the impact of this assumption may be minor during the projection period. For this reason, we suggest that PBGC staff first quantify the likely effect of adding mortality risk to the model before adding this to a future improvements list.

\section{Conclusions}

The pressures to develop and use the ME-PIMS model are increasing due to the rapid deterioration of the multiemployer program finances and the need to enact replacement legislation for the expiring multiemployer provisions under PPA. We agree with the Category 1 
recommendations of the ME-PIMS peer review panel, and strongly suggest that ME-PIMS be the highest development priority for PBGC resources. It is also important that PBGC undertakes changes while recognizing the need to address system, documentation, and ease of use issues, all of which are important in being able to produce high quality analysis under high pressure and short timeframes.

Here we have noted several areas of concern in SE-PIMS regarding the modeling of employer contributions, the link between PIMS and PBGC risk mitigation strategies, the modeling of future rates of benefit accrual, and PBGC's mortality assumption development. Since time and resources are constrained, we suggest that PBGC quantify the upper and lower bounds of these issues and prioritize changes in the model based on this information. 


\section{References}

Banham, R. (2013). “The Great Pension Derisking,” CFO Magazine. April 15.

http://www3.cfo.com/article/2013/4/retirement-plans_derisking-defined-benefit-pensionplans

Buck Consultants (2012). “ME-PIMS Peer Review Report,” Letter from Buck Consultants to Larry Shirley of the Pension Benefit Guaranty Corporation. Berwyn, PA: Buck Consultants, September 12.

DeFrehn, R. G., and J. Shapiro (2013). “Solutions Not Bailouts: A Comprehensive Plan from Business and Labor to Safeguard Multiemployer Retirement Security, Protect Taxpayers and Spur Economic Growth." A Report on the Proceedings, Findings and Recommendations of the Retirement Security Review Commission of the National Coordinating Committee for Multiemployer Plans (NCCMP). Washington, DC: NCCMP. http://webiva-downton.s3.amazonaws.com/71/59/b/39/1/Solutions_Not_Bailouts.pdf

Lynchval Systems (2012). “Multiemployer PIMS Known Limitations in ME-PIMS.”

Pension Benefit Guaranty Corporation (PBGC) (2000). “PBGC’s Early Warning Program.” Technical Update 00-3. Washington, DC: PBGC. http://www.pbgc.gov/res/other-guidance/tu/tu00-3.html

Pension Benefit Guaranty Corporation (PBGC) (2009). “PIMS Multiemployer Technical Specification - Model PBGC Net Position in ME-PIMS.” Washington, DC: PBGC.

Pension Benefit Guaranty Corporation (2010). “PIMS System Description for PIMS SOA ‘Core’ vFY09.1 Version 1.0.” Washington, DC: PBGC. 
Pension Benefit Guaranty Corporation (PBGC) (2012a). Annual Report 2012. Washington, DC: PBGC.

http://pbgc.gov/documents/2012-annual-report.pdf

Pension Benefit Guaranty Corporation (PBGC) (2012b). “A Brief History of PIMS.” Washington, DC: PBGC.

Pension Benefit Guaranty Corporation (PBGC) (2012c). October 2012 Guidelines for Enforcement of ERISA section 4062(e). Washington, DC: PBGC. http://www.pbgc.gov/Documents/4062(e)-enforcement-of-guidelines.pdf

Pension Benefit Guaranty Corporation (PBGC) (2013a). PBGC Insurance of Multiemployer Pension Plans -Report to Congress required by the Employee Retirement Income Security Act of 1974, as amended. Washington, DC: PBGC. http://www.pbgc.gov/documents/pbgc-five-year-report-on-multiemployer-pensionplans.pdf

Pension Benefit Guaranty Corporation (PBGC) (2013b). PBGC Pension Insurance Data Book, 2011. Washington, DC: PBGC. http://www.pbgc.gov/documents/pension-insurance-data-tables-2011.pdf Society of Actuaries Group Annuity Experience Committee (1996). “Group Annuity Mortality,” Transactions of the Society of Actuaries 1993-94 Reports: 3-41.

Society of Actuaries (2011). “The Rising Tide of Pension Contributions Post-2008: How Much and When?” Schaumburg, IL: Society of Actuaries http://www.soa.org/files/research/projects/research-2011-10-rising-tide-report.pdf 


\section{Ratio Net Position to Total Premium Revenue}

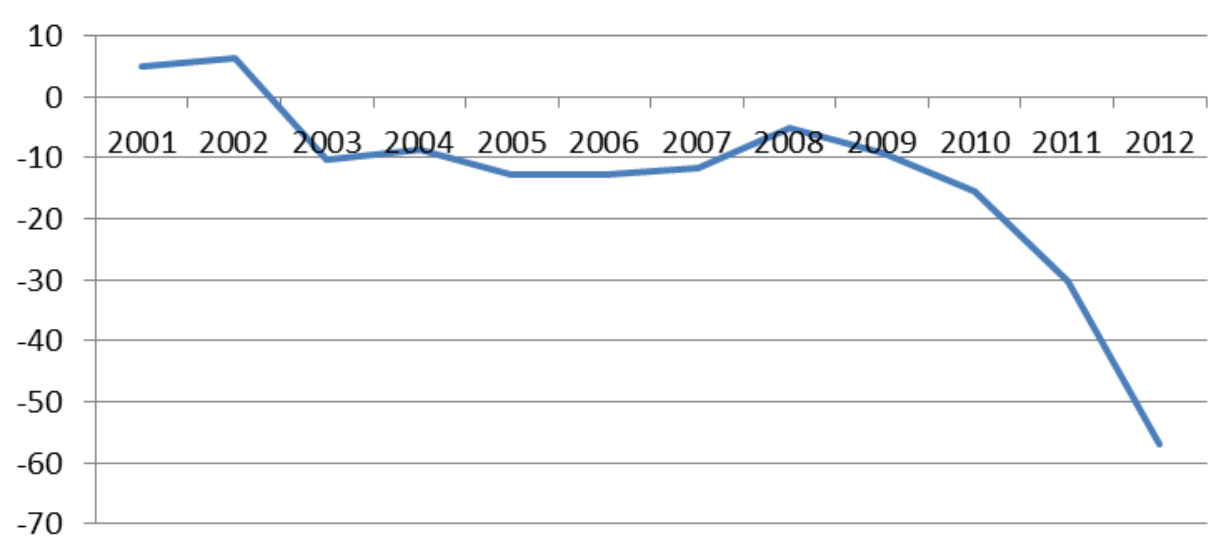

Figure 1. Multiemployer program - ratio of PBGC's fiscal position to premium income. Source: PBGC (2012a, 2013b). 


\section{Ratio Net Position to Total Premium Revenue}

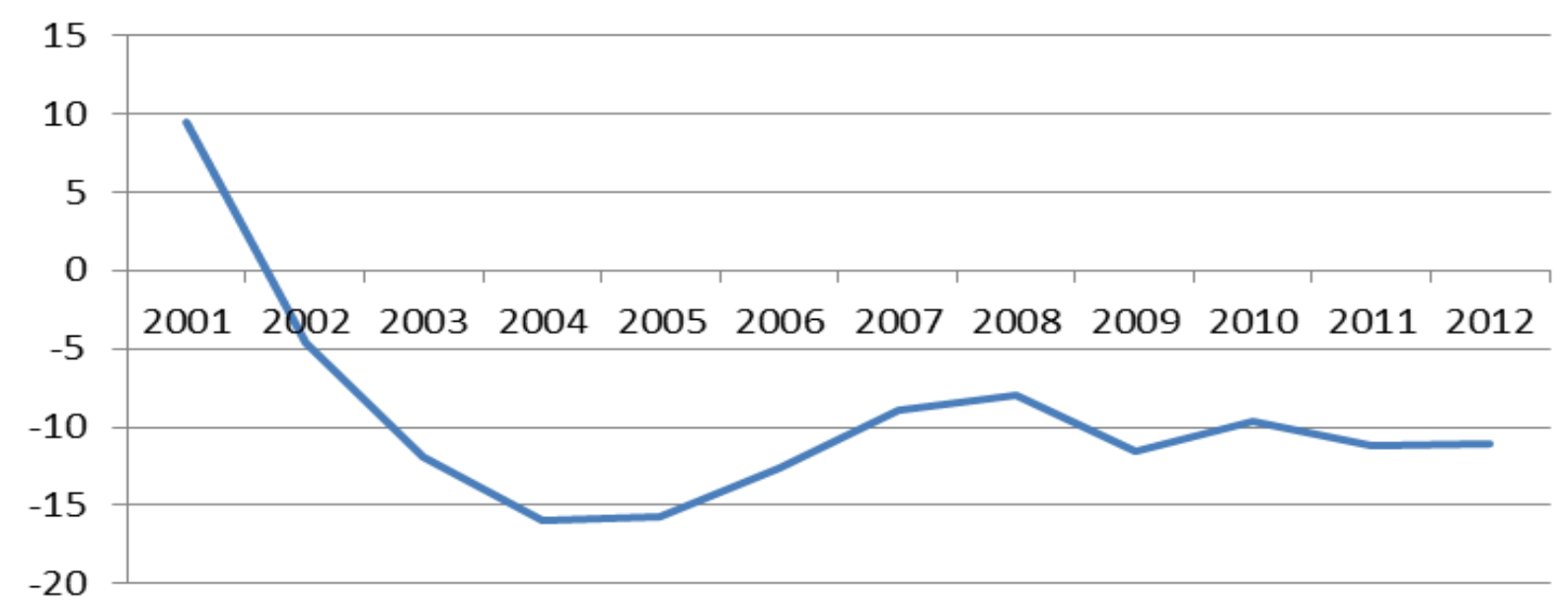

Figure 2. Single employer program - ratio of PBGC's fiscal position to premium income. Source: PBGC (2012a, 2013b). 
HISTORICAL CONTRIBUTIONS (2000 - 2009)

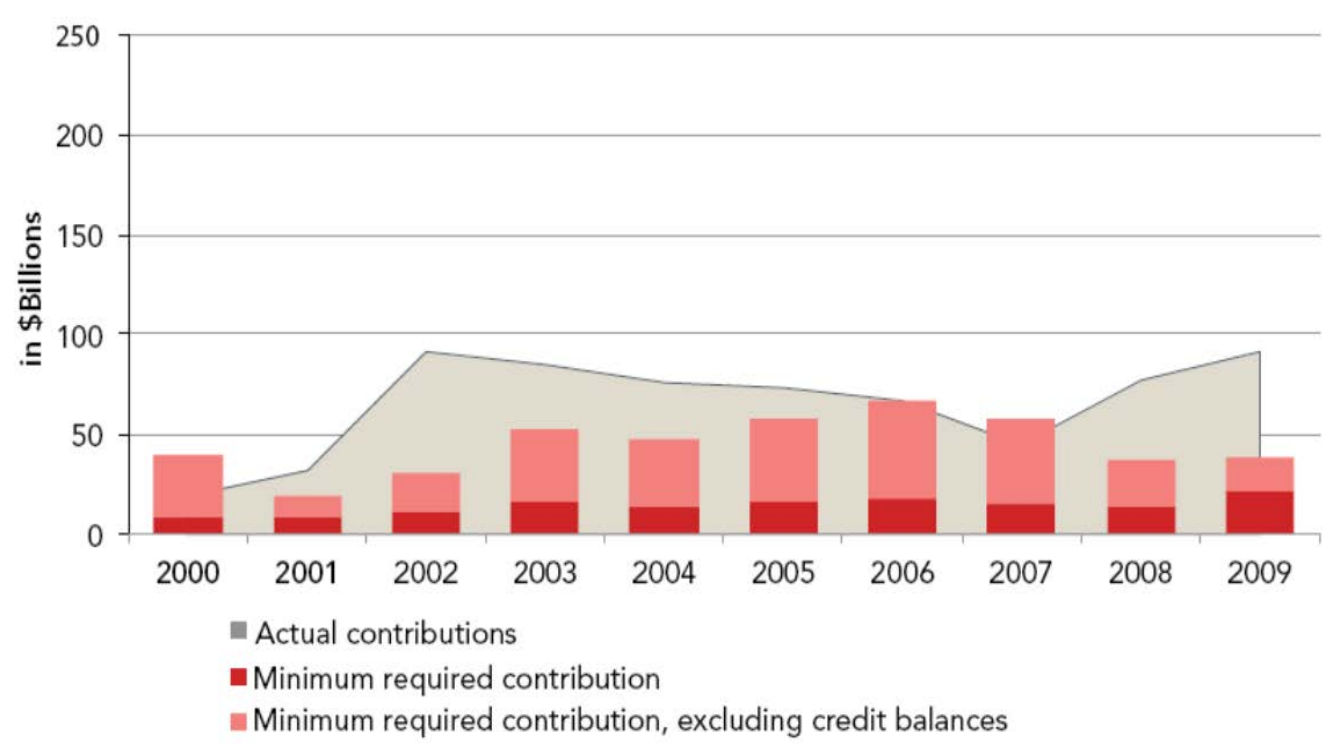

Figure 3. Single employer program - contributions vs. minimum required contributions. Source: Society of Actuaries (2011). 